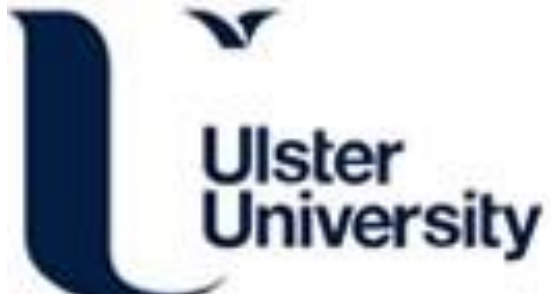

Recent advances in self-assembled nanoparticles for drug delivery

Verma, L. T., Singh, N., Gorain, B., Choudhury, H., Tambuwala, M. M., Kesharwani, P., \& Shukla, R. (2020). Recent advances in self-assembled nanoparticles for drug delivery. Current Drug Delivery, 17(4), 279-291. https://doi.org/10.2174/1567201817666200210122340

Link to publication record in Ulster University Research Portal

\section{Published in:}

Current Drug Delivery

Publication Status:

Published (in print/issue): 10/02/2020

DOI:

$10.2174 / 1567201817666200210122340$

\section{Document Version}

Author Accepted version

\section{General rights}

Copyright for the publications made accessible via Ulster University's Research Portal is retained by the author(s) and / or other copyright owners and it is a condition of accessing these publications that users recognise and abide by the legal requirements associated with these rights.

\section{Take down policy}

The Research Portal is Ulster University's institutional repository that provides access to Ulster's research outputs. Every effort has been made to ensure that content in the Research Portal does not infringe any person's rights, or applicable UK laws. If you discover content in the Research Portal that you believe breaches copyright or violates any law, please contact pure-support@ulster.ac.uk. 


\title{
Recent Advances in Self-Assembled Nanoparticles for Drug Delivery
}

\author{
Lanke Tejesh Varma ${ }^{1}$, Nidhi Singh ${ }^{1}$, Bapi Gorain ${ }^{2}$, Hira Choudhury ${ }^{3}$, Murtaza M. Tambuwala ${ }^{4}$, Prashant \\ Kesharwani $^{5, *}$ and Rahul Shukla ${ }^{1, *}$
}

\begin{abstract}
${ }^{I}$ Department of Pharmaceutics, National Institute of Pharmaceutical Education and Research (NIPER, Raebareli), Raebareli (U.P), India; ${ }^{2}$ School of Pharmacy, Faculty of Health and Medical Sciences, Taylor's University, Subang Jaya, Selangor, 47500, Malaysia; ${ }^{3}$ Department of Pharmaceutical Technology, School of Pharmacy, International Medical University, Malaysia; ${ }^{4}$ SAAD Centre for Pharmacy and Diabetes, School of Pharmacy and Pharmaceutical Science, Ulster University, Coleraine, County Londonderry, BT52 1SA, Northern Ireland. United Kingdom; ${ }^{5}$ School of Pharmaceutical Education and Research, Jamia Hamdard (Hamdard University), New Delhi, INDIA-110062
\end{abstract}

\begin{abstract}
The collection of different bulk materials forms the nanoparticles, where the properties of the nanoparticle are solely different from the individual components before being ensembled. Selfassembled nanoparticles are basically a group of complex functional units that are formed by gathering the individual bulk components of the system. It includes micelles, polymeric nanoparticle, carbon nanotubes, liposomes and niosomes, etc. This self-assembly has progressively heightened interest to control the final complex structure of the nanoparticle and its associated properties. The main challenge of formulating self-assembled nanoparticle is to improve the delivery system, bioavailability, enhance circulation time, confer molecular targeting, controlled release, protection of the incorporated drug from external environment and also serve as nanocarriers for macromolecules. Ultimately, these self-assembled nanoparticles facilitate to overcome the physiological barriers in vivo. Self-assembly is an equilibrium process where both individual and assembled components are subsisting in equilibrium. It is a bottom up approach in which molecules are assembled spontaneously, non-covalently into a stable and welldefined structure. There are different approaches that have been adopted in fabrication of self-assembled nanoparticles by the researchers. The current review is enriched with strategies for nanoparticle selfassembly, associated properties, and its application in therapy.
\end{abstract}

A R T I C L E H I S T O R Y

Received: June 11, 2019

Revised: September 28, 2019

Accepted: January 14, 2020

DOI:

$10.2174 / 1567201817666200210122340$

Keywords: Self-assembly, driving forces, nanoparticle, mesoporous silica nanoparticle, gold nanoparticle, liposome.

\section{INTRODUCTION}

In the current field of pharmaceutical research, nanoparticular drug delivery system has established itself as a promising tool in nanotechnology, where the nanoscale formulation can lead to a potential increase in delivery efficiency [13]. Development of nanoparticular delivery has been extended towards the delivery of chemotherapeutics to obtain superior efficacy with reduced toxicity of the cytotoxic drugs $[1,4]$. These modern delivery systems overcome the boundaries of larger biodistribution, unfavourable pharmacokinetics, and unfavourable physicochemical properties $[5,6]$. Mechanisms of absorption for the nanoparticular deliveries into the site of disease action, through an endocytotic pathway either by

\footnotetext{
*Address correspondence to these authors at the Department of Pharmaceutics, National Institute of Pharmaceutical Education and Research (NIPER, Raebareli), Raebareli (U.P), India; E-mail: rahulshuklapharm@gmail.com; rahul.shukla@niperraebareli.edu.in

School of Pharmaceutical Education and Research, Jamia Hamdard (Hamdard University),New Delhi, INDIA-110025; Tel/Fax: +91-7582244432; E-mail:prashantdops@gmail.com; prashant_pharmacy04@rediffmail.com
}

specific mechanisms (like receptor-mediated endocytosis) or by non-specific interactions (like adsorptive endocytosis with cell membranes) overcome the intracellular barriers, like endosomes and thus directly delivers the therapeutics into the cytosol for the desired pharmacological action [7, 8]. To avoid undesired toxicities, mainly of chemotherapeutics, these nanocarriers can be targeted with specific ligands on the surface towards disease specific sites by size-dependent passive or active targeting $[9,10]$. Alternatively, these nanoparticular deliveries can penetrate well into the tissues due to their nano-ranged size and thus, can be administrated intravenously with less irritation at the injection site[11].

Nowadays, spontaneous organisation of the discrete components of nanoparticles provides a platform for potential biomedical and pharmaceutical applications $[12,13]$. Such microscopic ordered organisation of components or self-assembly is characteristically associated with thermodynamic equilibrium with the advantages of improving bioavailability of poor bioavailable therapeutics, targetability to the disease site, controlled release for extended action, enhanced circulation time, provide protection to the drug from the external environment, serving as carriers for macromole- 
cules like proteins, peptides, nucleic acids, hydrophilic and lipophilic drugs. In the present scenario, various selfassembly nanostructures have been synthesized from biomaterials such as carbohydrates, nucleic acids, peptides, etc., for their biomedical as well as pharmaceutical applications [14-17]. Colloidal based drug delivery systems provide controlled delivery as well as targeted drug delivery at the site of cell. Drug targeting with nano-based technology will enable targeting of drug to a specific site, in short controlling the fate of drug in biological system. Advantage over conventional therapy is their effective uptake by cells. Another advantage of conventional therapy is that nanosystems can be developed according to biological interactions with system, targeting cell-surface receptors, targeting specific cell population, controlling the drug release at site, maintaining the therapeutic concentration of drug at the site. The present review provides an overview of different methods, interactions and recent development on nanoparticle self-assembly with the current advancements in technological applications.

\subsection{Self-assembly}

Self-assembled nanostructured constituents are frequently stimulated by nature as most of our biological structures are the product of self-assembly. The conventional method of fabrication for the drug delivery tools involves a series of chemical reactions between chemical molecules, and further to modify with targeting moiety, ligands are conjugated with the colloidal nanocarriers. Recent advancement in nanotechnology leads towards the development of self-assembled nanostructured systems. Programmable self-assembly of molecular building blocks is an extremely necessary means of accomplishing bottom-up control over novel functions and materials. The intermolecular interactions between the drug and ligands in self-assembled drug delivery tool does not impact on its inherent activities [18]. This assembling approach for the pharmaceuticals cuts the purification stage(s) of the final products, and also removes unwanted reactants and their by-products [19]. Basically, self-assembly is a bottom-up process, generally in which reactant molecules spontaneously, and/or non-covalently assemble into a welldefined and stable nanostructure due to direct specific interactions and/or indirectly, through their environment [20]. Alternatively, thermodynamics and other limitations like energy, entropy, templates (surface-modified substrates, containing active sites, which can selectively induce nanoparticle deposition), applied external fields to some extent controls the self-assembly. Among the above-mentioned factors, templates and applied fields aids directed self-assembly. Interfacial or surface tension forces that are acting on the interfaces leading to directed self-assembly [21]. It is a balanced process that maintains equilibrium between repulsive and attractive forces between molecules (Fig. 1).

The thermodynamics of the self-assembly process can be represented by a simple Gibbs Free-Energy equation.

$\Delta \mathrm{G}_{\mathrm{SA}}=\Delta \mathrm{H}_{\mathrm{SA}}-\mathrm{T} \Delta \mathrm{S}_{\mathrm{SA}}$

Gibbs free energy is available in the system; it is collectively termed as the addition of enthalpy $(\Delta \mathrm{H})$ and the multiplication of temperature $(\mathrm{T})$ and entropy $(\Delta \mathrm{S})$ of the system. The value of $(\Delta \mathrm{G})$ is always negative as it represents the spontaneous reaction occurring in the system (means no re- quirement of superficial energy input) and if the value is positive, then the reaction occurrence is nonspontaneous (means superficial energy is important for reaction).

- $\Delta \mathrm{G}<0$ : reaction is exergonic

- $\Delta \mathrm{G}=0$ : system is in equilibrium

- $\Delta \mathrm{G}>0$ : reaction is endergonic

Most self-assembly processes are enthalpy driven but in certain cases, it is entropy driven [22].

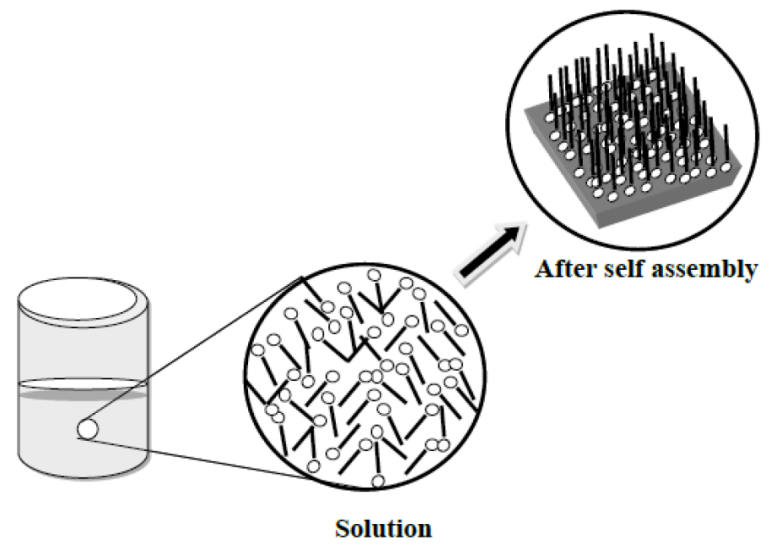

Fig. (1). Self-assembly of nanoparticles.

\section{DRIVING FORCES FOR SELF-ASSEMBLY OF NANOSTRUCTURES}

As discussed above, self-assembly is a balanced process in which well-defined arrangements are spontaneously formed from building blocks. Driving force is termed as the affinity of the system to attain thermodynamic stability, which means it is similar to the chemical potential of same molecule in dissimilar supramolecular system. The driving force is explained by equation: combined

$\mu=\mu^{\circ}+\mathrm{KT} \log \mathrm{X}_{\mathrm{I}}=\mu_{\mathrm{N}}^{\circ}+\frac{\mathrm{KT}}{\mathrm{N}} \log \left[\frac{\mathrm{X}_{\mathrm{N}}}{\mathrm{N}}\right]$

Where,

$\mu_{N}^{\circ}=$ mean value of free energy of molecule

$\mathrm{X}_{\mathrm{N}}$

$=$ concentration of combined supramolecular compound.

The most important forces that drive self-assembly are non-covalent interactions that include Vander-Waals interactions, steric and depletion forces, coordination bonding, hydrophobic forces, electrostatic interactions, hydrogen bonding, $\pi$ - $\pi$ staking interactions and solvation and hydration forces $[20,23]$. Strong dipole-dipole interaction with greater extent of selectivity and spatial arrangement is important in the production of self-assembled structure [24].

Most common stimuli directing self-assembly include $\mathrm{pH}$, light, ionic strength, solvent polarity, temperature, electromagnetic radiation, or redox activity that can be used for spatial distribution of the particles, either via straight forward intermolecular interactions or on top of predefined templates.

\subsection{Hydrophobic Effect}

The hydrophobic effect is most important among various non-covalent interactions in the self-assembly process. 
In general, the building blocks in self-assembly are amphiphilic molecules, comprising many synthetic building blocks and biomolecules like proteins and lipids. As both polar and non-polar regions coexist, the self-assembly of amphiphilic molecules can be readily aided by thermodynamics.

\subsection{Electrostatic Interactions}

Electrostatic forces like attraction and repulsion between ions, charged atoms or molecules also have a strong effect on self-assembly. Anionic proteins, genes and cationic polymers interact with each other through electrostatic interactions and form stable nanoparticles in aqueous solutions like in the case of a water-soluble cationic conjugated polymer that can bind to DNA by both electrostatic interactions and hydrophobic effect.

\subsection{Hydrogen Bond}

An electrostatic attraction between Hydrogen atom and a highly electronegative atom such as Nitrogen, Oxygen, or Fluorine is commonly known as hydrogen bonding. Hydrogen bonding has a vital part in the formulation of polymer sciences, affecting their morphological properties. Alteration in hydrogen bonding changes the structural properties of polymers and affects degree of polymerization. Hydrogen bonding can exist both in between molecules and within molecules. Hydrogen bonding is pervasive in inorganic molecules as well as organic molecules. For example, the nano particulates formed by peptides, hydrogen bond exists between the amides and carbonyls in the backbone of sheets that are formed by the self-assembly and increases the stability of the formulation (Table 1).

\section{SELF-ASSEMBLED NANOSTRUCTURES}

\subsection{Polymeric Nanostructures}

In the field of drug delivery, polymeric nanostructures are the prime area of interest for the formulation scientistsfor a long time. It has been established that the nanocarriers fabricated by polymers can improve the solubility of hydrophobic drugs and reduce the drug associated toxicities on non-target tissues. These formulations can also prolong the circulation time of drugs in systemic circulation and improve therapeutic efficiency. The polymers commonly adopted in the development of nanoformulations are usually nontoxic and biocompatible [25]. Chitosan, heparin and dextran are the few examples of natural polymers that have been well investigated for drug delivery [26-28]. Polyesters, polycarbonates, polyamides, and polyphosphazenes are among the commonly used synthetic polymers [29-32]. Along with the improvement of solubility of various hydrophobic drugs, these self-assembled nanoparticles of polymeric amphiphiles can preferentially accumulate in solid tumours by enhanced permeability and retention (EPR) effect when administered into the systemic circulation [33]. This section of the article will mainly focus on various polymeric nanostructures in the improvement of efficacy and safety in the delivery of pharmaceuticals.

Table 1. Classification of self-assembled nanoparticulates.

\begin{tabular}{|c|c|c|}
\hline Polymeric nano particulates & $\begin{array}{l}\circ \\
\circ \\
\circ \\
\circ \\
\circ \\
\circ\end{array}$ & $\begin{array}{l}\text { Micelles } \\
\text { Vesicles } \\
\text { Nanogels } \\
\text { Nanocapsules } \\
\text { Dendrimers } \\
\text { Stimulus sensitive polymeric nanoparticulates }\end{array}$ \\
\hline Lipid based nanoparticulates & $\begin{array}{l}\circ \\
\circ \\
\circ\end{array}$ & $\begin{array}{l}\text { Liposomes } \\
\text { Solid lipid nanoparticles } \\
\text { Niosomes }\end{array}$ \\
\hline Carbon based nanoparticulates & $\begin{array}{l}\circ \\
\circ \\
\circ\end{array}$ & $\begin{array}{l}\text { Graphene } \\
\text { Carbon nanotubes } \\
\text { Fullerenes }\end{array}$ \\
\hline Ceramic nanoparticulates & $\begin{array}{l}\circ \\
\circ \\
\circ \\
\circ\end{array}$ & $\begin{array}{l}\text { Silica } \\
\text { Calcium phosphate } \\
\text { Alumina } \\
\text { Titania }\end{array}$ \\
\hline Inorganic metal nanoparticulates & $\begin{array}{l}\circ \\
\circ \\
\circ \\
\circ \\
\circ\end{array} \quad$ & $\begin{array}{l}\text { Gold } \\
\text { Silver } \\
\text { Gadolinium } \\
\text { Zinc } \\
\text { Super paramagnetic oxides }\end{array}$ \\
\hline Biologicals based nanoparticulates & $\begin{array}{l}\circ \\
\circ \\
\circ\end{array}$ & $\begin{array}{l}\text { Peptide based } \\
\text { Nucleic acid based } \\
\text { Viral capsid based }\end{array}$ \\
\hline Miscellaneous & $\circ$ & Drug Based \\
\hline
\end{tabular}




\subsubsection{Self-assembled Polymeric Micelles}

Delivery of hydrophobic drugs has been targeted through amphiphilic micelles for decades because of the advantages of solubilising capacity, stability within the systemic circulation and capability of high drug loading [34]. Further, small size, unique core shell structure, and changeable surface chemistry made them a popular nanostructure in the field of nanotechnology. These micelles and/or liposomes mimic structures of the bio-membrane of human body, and can also contain macromolecules with both hydrophobic and hydrophilic regions [35]. It is known that the amphiphilic polymers at above critical micelle concentration (CMC) and critical micelle temperature (CMT), spontaneously form nanosized aggregates in the aqueous medium. The research on polymeric micelles has crossed the level of bench level research and reached the bedside of the patients. Most of the polymeric micelles in clinical trials consist of poly(ethylene glycol) and its derivatives [36, 37]. These polymeric micelles are useful to deliver therapeutics and peptides; however, the above-mentioned polymers are unable to formulate formulations for gene delivery. Alternatively, polyamidoamine (PAMAM) dendrimers, polyethylenimine and reducible poly (oligo-D-arginine) have been used in the delivery of genetic materials [38]. Hydrophobic modifications of PAMAM dendrimers and polyethylenimine has found to improve gene delivery [39]. It has been established that hydrophobic modification of the PAMAM dendrimers and polyethylenimine form micelles in the aqueous environment and thus found to be useful for delivering hydrophobic drugs $[39,40]$. Conversely, amphiphilic di-block (hydrophilic-hydrophobic) or tri-block (hydrophilic-hydrophobic-hydrophilic) copolymers are also employed in the preparation of self-assembled polymer micelles. Most of the self-assembled micelles of amphiphilic block copolymers have a diameter of 10 to $80 \mathrm{~nm}$ with a hydrophilic shell and a hydrophobic core which is a steric barrier for aggregation and prevent binding to proteins and opsonisation during the systemic administration which blocks the RES uptake (Fig. 2). Poly(ethylene glycol) and poly(ethylene oxide) are FDA approved and mostly used hydrophilic blocks [41]. Examples of block copolymers poly (L-amino acids), biodegradable poly(esters) e.g. poly(glycolic acid), poly(D-lactic acid), poly(D,L-lactic acid), copolymers of lactide/glycolide, and poly( - caprolactone), phospholipids/long chain fatty acids; and polypropylene oxide(pluronics / poloxamers) are the examples for tri-block-copolymers [42].

\subsubsection{Self-Assembled Polymeric Vesicles}

Hydrophilic and hydrophobic parts of the amphiphilic polymers form special alignment to create a pluriform aggregate [43]. Thus, like self-assembled polymeric micelles, such polymers can also tend to form polymeric vesicles. Such vesicles can be formed either by the self-assembly of polymers or from the polymerization of monomers following self-assembly. Block copolymers, random graft copolymers, etc. form polymeric vesicles. These self-assembled vesicles are nowadays at the leading nanotechnological tool with limitless possible uses, ranging from biomedical application to enzymatic reactors of nano-range [44].

Polymer self-assembly into vesicles is not a spontaneous process due to steric or ionic repulsion between head groups and normally requires application of external energy, such as probe sonication [45]. Minimum interfacial energy aids the formation of a closed spherical bilayered. In general, lesser hydrophobic amphiphiles form micelles, while amphiphiles of intermediate hydrophobicity form vesicles. The selfassembly of polymers into vesicles depends on the hydrophobic-lipophilic balance of polymers as seen in liposomes and niosomes. Few polymer specific factors, like the degree of polymerization, flexibility of the hydrophobic block in block copolymers have an impact on the ability to form vesicles. High degree of polymerization prevents vesicle formation. Polymeric vesicles possess good physical stability and are usually less susceptible to degradation by organic solvents and soluble surfactants, and are frequently less permeable to hydrophilic solutes, compared with vesicles prepared from low molecular weight amphiphiles [46].

The vesicles formed by the block copolymers possess superior physical and mechanical properties compared to the lipid-based vesicles [44]. Vesicles with higher molecular weight copolymers had shown an increase in robustness of the vesicle due to the increase in thickness of the vesicle membrane, which further leads to an increase in greater bending rigidities [44, 47]. However, it has been established that the membrane elasticity of phospholipid vesicles does not depend on the molecular weight [44]. Similarly,

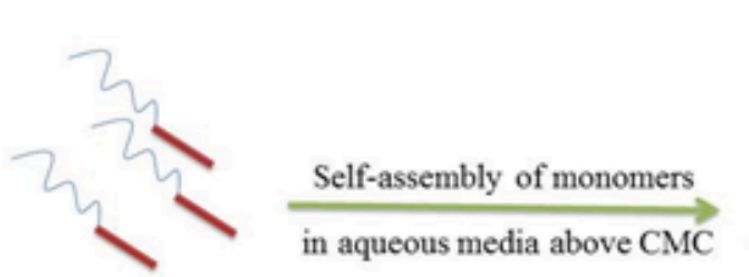

Amphiphilic block copolymer

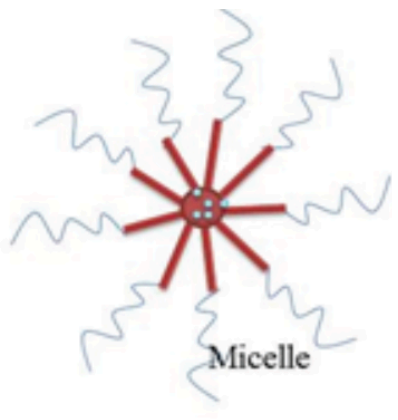

Hydrophilic part $\backslash$ Hydrophobic part $\because$ Hydrophobic drug

Fig. (2). Self-assembly of amphiphilic block copolymer in aqueous media. (A higher resolution / colour version of this figure is available in the electronic copy of the article). 
polymerizable vesicles forming monomers are used to prepare self-assembling nano-particulates. The advantages of this system are that they can be prepared and stored as dry powders and can be easily re-dispersed in the aqueous media to form 50-100 nm particles with less leaky, and thermostable properties [48].

\subsubsection{Polymeric Nanogels}

Application of nanogels has been extended towards several fields of research, such as diagnostic, sensing, bioengineering and most importantly, drug delivery [49]. Polymeric nanogels are usually nanosized polymer networks, with an affinity towards aqueous media to imbibe, inertness in systemic circulation, superior colloidal stability, and suitable for bulky drug incorporation [50]. Polymeric nanomicelles and nano vesicles carry a main disadvantage i.e. they are stable only above the critical micelle concentration (CMC), but below CMC they tend to dissociate into single polymer chains and have a loose drug carrying capacity. So to avoid this dissociation of the self-assembled nanostructures, linking the polymers to obtain nanogels which are more stable has become an effective approach in drug delivery system [51]. Another important advantage of the polymeric nanogels over the standard nanocarriers is the increased encapsulation of the therapeutics and offering of three dimensional microenvironment for the application in different therapeutic purposes, including tissue engineering [52].

This self-assembly nanogels preparation method is extensively useful where the controlled collection of amphiphilic or hydrophilic polymers forms the formulation due to the physicochemical interactions, such as electrostatic interactions, hydrophobic interactions, stereo-complexation or supramolecular chemistry and hydrogen bonding [42]. Kabanov and Vinogradov reported the use of labile disulfide bonds of cystamine as a biodegradable cross-linker through electrostatic interactions. Thus, besides the physical interactions between the molecules, a covalent cross-linking between the cross linking polymeric chains was utilized in the formation of a thermodynamically stable nanogel [53]. Alternatively, as described by Akiyoshi and colleagues, the hydrophobic interaction of cholesterol modified pullulan and insulin forms the nanosized hydrogels [54]. The presence of cross-linkers impact mainly on the swelling characteristic, morphology and pore size of the nanogels, which ultimately affect the release kinetics of the incorporated therapeutic entities. Thus, to achieve controlled delivery of the entrapped therapeutics, various stimulus responsive polymers are introduced where the polymers are cleavable under redox environment, $\mathrm{pH}$ change, enzyme, light, etc. Zhao et al. reported the formation of thermal- and photo-responsive core-shell nanogels via temperature sensitive self-assembly in aqueous solution of a double-hydrophilic block copolymer, followed by reversible photo-dimerization and photo-cleavage [55].

\subsubsection{Polymeric Nanocapsules}

Nanocapsules are sub-micrometer ranged hollow spherical structures which are composed of polymer shell with inner hollow space. These nanocapsules can be incorporated to improve the oral bioavailability of proteins and peptides. Encapsulation of therapeutic agents in nanocapsules is protected from degradation in the external adverse environment, at the same time it could provide a controlled release profile of the entrapped drug, reduces systemic toxicity, and mask the unpleasant taste [56]. Various methods have been adopted to formulate nanocapsules where the polymer shell is formed first over a template particle which is subsequently removed to obtain the inner hollow space [42].

Layer-by-layer self-assembly method is a popular method to formulate the outer polymeric shell on template particle. This was executed by charge surface of polyelectrolyte selfassemblies where the oppositely charged polyelectrolytes in a solution deposited over the template particle in a layer-bylayer pattern. The polymeric layer is formed on the template surface by electrostatic interactions. This deposition of the polyelectrolytes can be controlled to maintain the thickness of the polymeric cells [57]. Commonly used template particle for layer-by-layer electrostatic self-assembly is obtained by incorporating functionalized polystyrene latex particles. As the charge on the surface changes over the absorption of one electrolyte, another oppositely charged group of polyelectrolytes is then absorbed to get the layer-by-layer pattern. For example, low molecular weight polyglutamic acid and chitosan were alternatively assembled over sulfonated polystyrene beads by Dash and teams [58].

\subsubsection{Polymeric Dendrimers}

Dendrimers are three-dimensional, hyper branched spherical nanopolymeric structures (Fig 3), which have been successfully incorporated in various fields of therapy $[59,60]$. The major advantages of the dendritic deliveries include the nano size range, low polydispersity index, controlled molecular structure, modifiable surface with multiple functional groups, and ability to incorporate hydrophilic and lipophillic therapeutic agents within the interior cavities or outer surface of the three dimensional structure $[4,61]$. These dendritic structures are mostly synthesized by the convergent and the divergent methods, where the growth of the molecules starts from its periphery towards the core in convergent method, but the growth of the molecule in divergent method is initiated from the core, proceeds from the core towards periphery [62-64]. These two stepwise methods are tedious and timeconsuming because of several protection-deprotection and extensive purification steps. However, the divergent method is considered to be suitable for large scale synthesis and preparation of higher generation dendrimers [42, 65].

\subsection{Lipid Based Nanoparticulates}

\subsubsection{Self-assembled Liposomal Nanostructures}

Nanostructures fabricated with liposomes are the first drug delivery system on the nanoscale to make the transition from concept to clinical application. Liposomes incorporate both hydrophilic and hydrophobic materials in their respective compartments by nature. Along with this unique advantage, biocompatibility and biodegradability are the added advantages that make liposomes attractive as drug delivery vehicles. Liposomes can accumulate at sites with high vascular permeability when their average diameter is in the ultrafilterable range $(<200 \mathrm{~nm})$. Liposomes, in general, are thin, fragile, and thus not stable and also have limited use due to low encapsulation efficiency, rapid leakage and poor storage stability (Fig. 4a) [13, 66, 67]. 


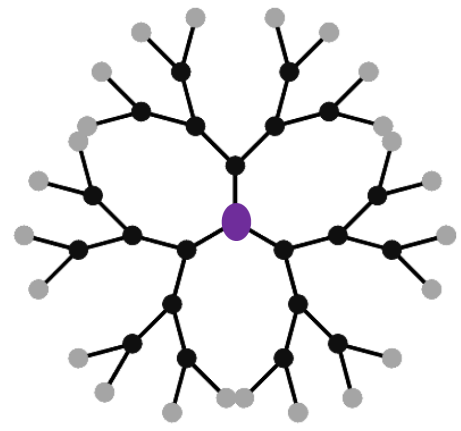

Fig. (3). Molecular arrangement of dendrimer. (A higher resolution / colour version of this figure is available in the electronic copy of the article).

Molecular self-assembly of the liposomal components forms the liposomal delivery by the non-covalent interactions. Spontaneous association of the amphiphilic liposomal components results in isolation of lipophilic fractions in an aqueous media, leading to the formation of a well-defined and stable supramolecular structure $[68,69]$. This is considered to be an important approach for the fabrication of biomaterials $[16,70]$. This could not be achieved by the bottomup process where contact between the required building blocks and obtaining the desired assembly is always challenging. Such control over self-assembly process could be achieved using electro spraying, a hydrodynamic atomization approach [70-72]. This process utilizes electrical energy to vaporize the solvent from a polymer solution; it is a topdown process which ultimately results in solid dispersion for the formation of submicron-ranged units. Electro spinning technique is also used to yield nanoscale fibres, similar to electro spaying, and thereby forms nanoscale objects from different components [73].

\subsubsection{Self-assembled Niosomes}

Niosomes are synthesized by the self-assembly of nonionic surfactants, often contains dicetyl phosphate, and cholesterol along with the surfactant. Associated properties and structural architecture of niosomes are similarto liposomal deliveries or biological complements comprising of biological phospholipids $[74,75]$. The self-assembly of non-ionic surfactants into niosomes is dependent on the hydrophilichydrophobic balance of the surfactant and a CPP between 0.5-10 enables niosomal self-assembly [76, 77]. Cholesterol component in the niosomes generally serves as a membrane stabilizer. Development of niosomal formulation in the la-

boratory is performed by mixing two liquid phases in a container for their spontaneous self-assembly to form the desired niosomes. Such self-assembly in the container could not control the mechanical and chemical environments, which results in niosomes with high polydispersity index [74, 78]. This scenario instigates the use of size-altering processes, such as sonication or extrusion, to obtain more homogenous niosomal particles.

\subsubsection{Self-assembled Lipid Polymer Hybrid Nanoparticle}

Self-assembly of lipid polymer hybrid nanoparticle provides a sturdy drug delivery platform with high drug loading efficiency, sonorous and sustained drug release behaviour, superior stability profile and promising targeting of various cells and tissue (Fig. 4b) [79, 80]. The structure of lipidpolymer-lipid hybrid nanostructure also consists of a charged hollow shell, a middle polymeric hydrophobic layer, and a neutral lipid outer layer. These are usually formulated by double-emulsion solvent evaporation technique and selfassembly method. Sometimes, the outer layer is modified with PEG to avoid immunological recognition of the developed nanoparticle. Incorporation of PEG could also help in particle stability in systemic circulation, controls the degradation of polymer and ultimately, release of an incorporated drug. The middle layer of the polymer also controls the entrapped therapeutic molecules and serves to deliver hydrophobic therapeutics. The inner hollow core also serves as carrier for the therapeutic agents [79].

\subsection{Carbon Based Nanoparticulates}

\subsubsection{Graphene}

Carbon atoms patterned a single layer in a hexagonal lattice, i.e., graphene has gained potential interest in the field of energy storage devices, catalysis, sensors, and environmental field (Fig. 5A) [81, 82]. Graphene has honeycomb like structure and follow $\mathrm{sp}^{2}$ hybridised lattice having zero energy band gap and characteristics like wider surface area, more conductivity and effective mechanical and chemical stability. Due to these characteristics, graphene serves as a suitable substrate for research purpose like in fuel cell catalysis, drug delivery and biosensing, etc. [83, 84]. Such atomic-scale honeycomb lattice offers good biocompatibility and has low cytotoxicity with excellent electronic, thermal, and mechanical properties. Thus, the two-dimensional structures of graphene and its functional derivatives are used well as building blocks for functional self-assembled carbon-based nanostructures. Among the functionalized structures, 1-
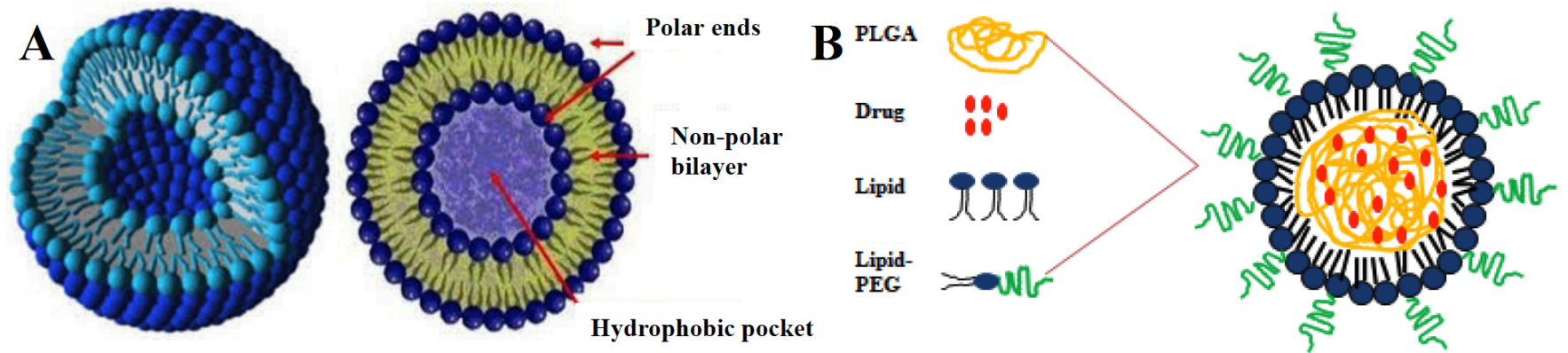

Fig. (4). Self-assembled lipid based nanostructures, A. Liposomes, and B. Lipid polymer hybrid nanoparticle. (A higher resolution / colour version of this figure is available in the electronic copy of the article). 
dimensional tube tube-in-tube nanostructures $[85,86]$, 2dimensional graphene film [87] and 3-dimensional graphene/polymer composites $[88,89]$ are widely researched worldwide. The presence of numerous oxygen containing functional groups on graphene oxide sheets make them easily processable and soluble for research. Worldwide research on these graphene sheets leads to the innovation of novel graphene-based materials, such as nanoparticle decorated 2dimensional graphene sheets $[90,91]$. Alternatively, 3dimensional graphene networks were developed by Chen and team with magnetic nanoparticles [92, 93]. Graphene has lipophilic property and does not dissolve in aqueous solvent, as it forms coagulates by van der waals interaction. Graphene products also have greater efficacy as compared to various types of carbon nanoparticles such as carbon nanotubes and fullerene. PEGylated conjugated graphene functionalized moieties were synthesised with rendering high solubility in aqueous based solutions for enhancing solubility of water insoluble compounds. Non-covalently bonded assemblies of graphene were formulated with cyclodextrins by entrapping drug as host and delivery to the specific sites. But graphene based self-assembly systems counterfeit with the issue of unknown mechanism for metabolic pathway followed for itself and its metabolites.
$\underline{\mathbf{A}}$

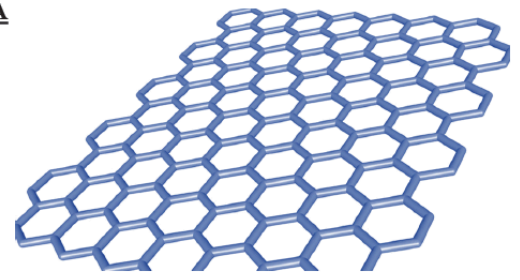

$\underline{\mathbf{B}}$

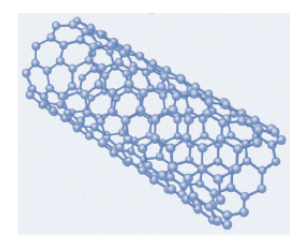

$\underline{\mathrm{C}}$

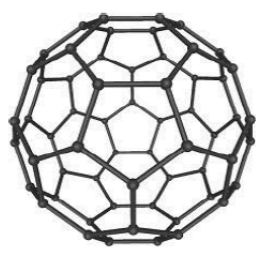

Fig. (5). Self-assembled carbon nanostructures, A. Graphene, B. Carbon nanotube, C. Fullerene. (A higher resolution / colour version of this figure is available in the electronic copy of the article).

\subsubsection{Carbon Nanotubes}

Carbon nanotubes (CNTs) (Fig. 5B) are carbon made tube shaped materials that look like a chicken roll with continuous hexagonal mesh and presence of graphene at the peaks of hexagonal structures [94]. Carbon nanotubes mainly belong to fullerene family, it is cylindrical in shape and generally one end is open but, in some cases, it is closed with full fullerene caps. The size of carbon nanotubes is from few nanometers to several micrometers (its length is approx. 50,000 times smaller than the width of normal human hairs) [94]. These are similar to graphene but have potential advantages over other nanocarriers because of its unique properties of large thermal conductivity, high electrical conductivity and mechanical properties [95]. Further, for drug delivery tools, small drug molecules can be loaded in their large inner hollow space of CNTs, whereas proteins and genes can be loaded on their outer surface by chemical modification [23]. Kim and colleagues had reported the self- assembly of a drug-peptide conjugate into a well-defined nanotube to obtain increased resistance against hydrolytic deactivation of the entrapped components and to get superior antitumor response of the incorporated drugs [96].

Carbon nanotubes family belongs to graphite and fullerene class; it is new elements of carbon allotrope groups. Similarly, super aligned CNTs are also used to formulate selfassembled carbon nano-sponge utilizing the compact, wellaligned, and clean surface properties of the super aligned CNTs [95]. A continuous and monolithic 3-dimensional network of the super aligned CNTs was formed by ultrasonication and co-deposition method. This network is only possible with super aligned CNTs because of the strong interaction between the nanotube molecules, however, this is not applicable to ordinary CNTs [95].

\subsubsection{Fullerene}

Nanomolecular carbon cages (Fig. 5C), fullerenes are a platform for the delivery of therapeutics or imaging agents. Fullerene basic structure contains carbon atoms in different forms such as hollow sphere and tubes. Fullerene has C60 structure, symmetric molecule with 20 hexagons and 12 pentagons, all the rings of fullerene are fused with conjugated double bond. They have tremendous conjugation but chemically and physically they act as electron scarce alkenes [97, 98]. Basic functional mode of fullerenes includes the role of drug delivery scaffold or vector, where the biologically active moiety may or may not be linked with the fullerene [97]. A protein and fullerene co-assembly has been reported by Kim and colleagues where the compatible interaction resulted via non-polar interaction between the two structures [99]. Such devices with conjugated polymers have also gained potential research interest in current years because of their fascinating properties, including flexibility of structure, lightweight, and low-cost production [98]. Fullerene based buckysomes self-assembling system was synthesised in size range of 100-200 $\mathrm{nm}$. These buckysomes based selfassemblies were explored for delivery of water-insoluble drugs especially anti-cancer drugs. Buckysomes bulky structures were feasible for encapsulating bulkier drug molecules. Fullerene can get entrapped within lipophilic cavity of HIV protease and inhibit the overindulgence amount of substrate present on enzyme catalytic site. Fullerenes have also property of radical scavengers and antioxidants, when fullerene is bare under light it forms singlet oxygen. In pharmaceutical industry fullerenes have wide application in drug delivery system and as a carrier in gene delivery.

\subsection{Ceramic Nanostructures}

Inorganic compounds like silica, calcium phosphate, alumina, Titania, etc. can be fabricated into porous nanostructures which are biocompatible. It includes mesoporous silica nanostructures and calcium phosphate-based nanostructures and is recently applied nanostructured assemblies in research.

\subsubsection{Mesoporous Silica Nanostructures}

Mesoporous silica nanoparticle has a solid rigid outline with high specific surface area, adjustable pore size and diameter, and versatile functionalization, which helps to attach different functional groups of drug molecule to targeted site. 
Chemically MSN is honeycomb like structure with an active surface. MSNs are wide spread due to its higher drug loading tendency and fewer side effects, the silica present in MSNs has more biocompatibility than other metal oxides such as titanium and iron oxides. Mechanism of generation of drug loaded silica based mesoporous nanoparticles is simply by diffusion. Drug molecules are suspended in a solvent along with mesoporous silica or melting drug liquid is poured on silica. Application of concentration gradient allows the diffusion of drug molecules into pore. The mesoporous structure of silica has an exclusive property specially its greater drug loading capacity and strong Si-O bonds of mesoporous silica nanoparticle provide stability and prevent it from degradation. Hence, MSNs are more stable than other nanoparticulates formulations such as liposomes, niosomes and dendrimers [100]. A wide variety of drugs have been loaded or covalently grafted in it. Folate, mannose, galactose functionalized MSNs have been reported to induce higher cytotoxicity in cancer cells. The mesoporous nanoparticulates are formulated either by simple sol gel method or by spray dry technique (Fig. 6).

\subsubsection{Calcium Phosphate Nanostructures}

Hydroxyapatite and tricalcium phosphates are the compounds which have calcium phosphate, chemical similarity to the bone and are biocompatible. Along with biocompatibility it also offers controlled release and has variable surface charge density. Scientists successfully synthesised mono dispersive nanoparticles of Calcium phosphate surrounded by hydrophilic polymeric chains. Calcium phosphate nanoparticles (CPNPs) are used for DNA transfection because of their good penetration through cell membrane, stay and bound with transfecting DNA inside the cell hence, protecting the DNA from lysosomal enzyme so the DNA is stably retained in cell cytosol until it translocates into the nucleus. CPNPs are biocompatible in nature because bone and teeth contain calcium phosphate and tend to bind with DNA hence it is recognised under second generation vector for proficient delivery of gene within the cell. Calcium phosphate nanoparticles are multilayer shell nanoparticles which include calcium phosphate core followed by DNA layer and then additionally pursued by calcium phosphate shell. This type of multilayer shell shield the DNA from degradation by nuclease/lysosome. CPNPs are prepared by various methods such as co-precipitation, sol-gel synthesis, electrodeposition and microemulsion [101].

\subsection{Biologicals Based Nanoparticulates}

\subsubsection{Peptides-based Nanostructures}

Peptides have advantages like biocompatibility, biodegradability, low cost, tunable bioactivity, high drug loading capacities, chemical diversity, site specific targeting and stimuli responsive drug delivery at disease sites. Various nano-based structures like nanoparticles, nanotubes, nanofibers, and hydrogels have been synthesized [14]. Naturally occurring self-assembly motifs present in proteins such as $\alpha$ helices, $\beta$-sheets and coiled-coils can be used to drive the self-assembly process, peptides can form well-defined nanostructures of any size and shape. Additionally peptide functionalization can easily be performed by introducing various compounds to the peptide structure. Self-assembled peptides (SAPs) are the smart delivery systems with an approach for intracellular uptake, targeting, controlled release and enhanced biological functionality. SAPs might interact with protein assemblies or protein present in certain cells to strategically target and manipulate the fate of cell. SAPs based delivery systems can be formulated in the form of nanotubes, vesicles and hydrogels for delivering the anticancer moieties to specific cancerous site.

\subsubsection{Nucleic Acids Based Nanostructures}

Preparation of cationic lipid-nucleic acid nanoparticle from a liquid monophase containing water and a water miscible organic solvent where both lipid and DNA components are separately soluble prior to their combination was reported. Upon removal of the organic solvents, stable and homogeneously dispersed (70-100 nm) lipid-nucleic acid nanoparticles (Genospheres) were formed [102]. Nucleic acid is an extensively used bio-material in nanoformulations because it holds mainly carbonyl and amino moiety on the surface of nucleoside chain and this helps to coordinate with metal ion. The negatively charged phosphate group present on surface retard the irreversible coagulation of nanoparticles and gather metal ion alongside the nucleic acid framework through electrostatic interaction. Nucleic acid has the ability to form stable and adaptable metal nanoparticles. In current scenario, nucleic acid based nanostructure sets up an enormous potential in the field of nano-biotechnology particularly in drug delivery and cellular imaging. For example, DNA block co-
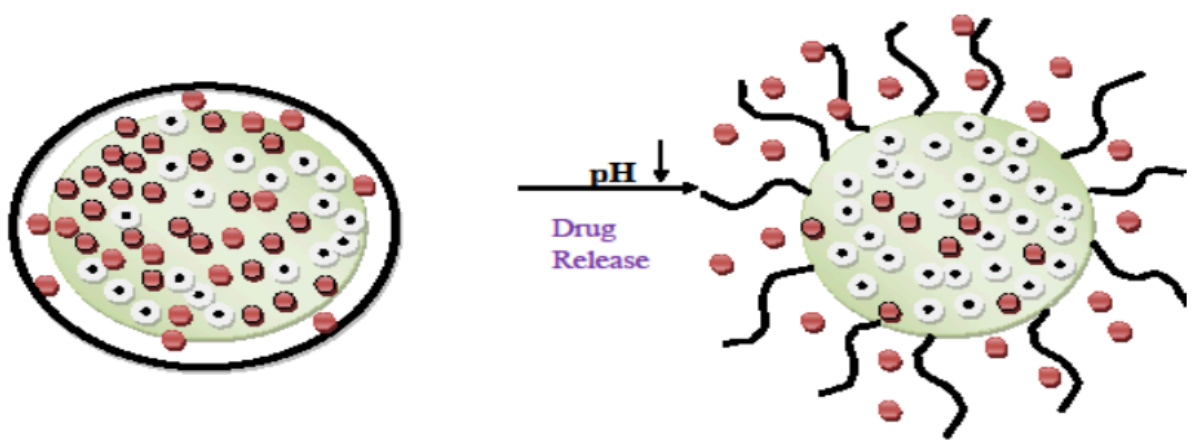

O: Drug : Polymer

Fig. (6). Self-assembled mesoporous silica nanoparticles. (A higher resolution / colour version of this figure is available in the electronic copy of the article). 
polymer micelles play a vital role in cancer nanotechnology and in novel drug delivery system to deliver drug at specific site [103]. Poly (ethylene imine) PEI is most widely used polymer in nucleic acid based nanostructure drug delivery [104].

\subsection{Miscellaneous}

\subsubsection{Drug-based Nanostructures}

Some small molecule drugs have the property to show reversible self-assembly behaviour, which can be used to form supramolecular nanostructures of well-defined size and shape. Amphiphilic prodrugs can be synthesised by conjugating hydrophilic polymers with hydrophobic drugs and these prodrugs can be used to prepare stable nanostructures spontaneously by self-assembly. In this way, a self-delivery system can be obtained and it can provide a sustained drug release $[105,106]$.

\subsubsection{Inorganic Metal Nanostructures}

Metallic nanoparticles, such as gold, silver, gadolinium, and iron oxide are the inorganic metal nano structures which are under study for drug delivery and targeting. Gold nanoparticles (AuNPs) gain much more interest in this era due to their properties like excellent biocompatibility, higher stability inside the cell, simple surface modification and flippant synthesis process. Gold nanoparticles of different shapes such as rod shape, dumbbells and dog bone shape are formulated via seed mediated method. Change in $\mathrm{pH}$ and presence of silver $\left(\mathrm{Ag}^{+}\right)$ion affect processing of gold $(\mathrm{Au})$ nanoparticles [107] (Fig. 7).

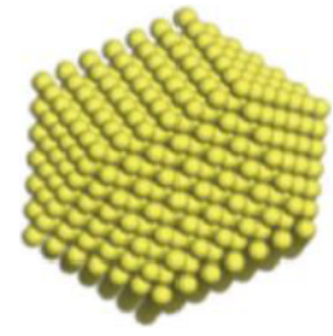

Fig. (7). Self-assembled gold nanoparticles. (A higher resolution / colour version of this figure is available in the electronic copy of the article).

\section{FUTURE PERSPECTIVES}

This review discussed various examples related clearly to the significant advances related to the field of nano based drug delivery and effectiveness in relation to self-assembly based drug delivery systems. Examples cover both temporal and spatial targeting of self-assembled nanovectors. Future challenge is combining all the features of above discussed self-assembled systems into one system and achieving particular needs with further attachment with special ligands for active targeting or pulsatile release behaviour. These selfassembled nanovectors can be employed for therapeutic intervention in cancer, anti-retroviral therapy, gene therapy, antibiotic therapy with better potential. Further, the potential of these self-assembled drug delivery systems is not fully explored and limited to application in auxiliary moieties. Recent development in self-assembling drug delivery sys- tems will open the doors to new ways of future drug delivery and exciting for formulation scientists.

\section{CONCLUSION}

Self-assembled nanoparticles have a tendency to form well defined structure driven by various non-covalent interaction like van der-waals interaction, hydrophobic forces, electrostatic interaction, hydrogen bonding and $\pi-\pi$ staking interaction. In recent research it was found that selfassembled nanoparticles synthesized by using several biomaterials such as carbohydrates, peptide and protein play an important role in siRNA and gene delivery. Self-assembled nanostructure could serve a wide variety of functions including controlled and targeted drug delivery, long circulation, reduce side effects, and provide stability to formulation, enhance penetration and due to their smaller size allow the delivery via intravenous routes. However, formulation scientists are still facing lots of hurdles in delivering a drug through self-assembled nano formulation because of their stability issue, and molecular weight (in case of protein and peptide drugs). In recent scenario, self-assembled nanoparticles have the potential for site specific targeting by minimizing peripheral tissue toxicity hence, boost drug delivery systems.

\section{CONSENT FOR PUBLICATION}

Not applicable.

\section{FUNDING}

None.

\section{CONFLICT OF INTEREST}

The authors declare no conflict of interest, financial or otherwise.

\section{ACKNOWLEDGEMENTS}

The authors acknowledge the Department of Pharmaceuticals, Ministry of Chemicals and Fertilizers, Govt. of India. The NIPER-R communication number for this article is NIPER-R/Communication/078.

\section{REFERENCES}

[1] Gorain, B.; Choudhury, H.; Pandey, M.; Kesharwani, P. Paclitaxel loaded vitamin E-TPGS nanoparticles for cancer therapy. Mater. Sci. Eng. C, 2018, 91, 868-880.

http ://dx.doi.org/10.1016/j.msec.2018.05.054 PMID: 30033322

[2] Kesharwani, P.; Gorain, B.; Low, S.Y.; Tan, S.A.; Ling, E.C.S.; Lim, Y.K.; Chin, C.M.; Lee, P.Y.; Lee, C.M.; Ooi, C.H.; Choudhury, H.; Pandey, M. Nanotechnology based approaches for anti-diabetic drugs delivery. Diabetes Res. Clin. Pract., 2018, 136, 52-77.

http ://dx.doi.org/10.1016/j.diabres.2017.11.018 PMID: 29196152

[3] Jain, A.; Sharma, G.; Ghoshal, G.; Kesharwani, P.; Singh, B.; Shivhare, U.S.; Katare, O.P. Lycopene loaded whey protein isolate nanoparticles: An innovative endeavor for enhanced bioavailability of lycopene and anti-cancer activity. Int. J. Pharm., 2018, 546(1-2), 97-105.

http ://dx.doi.org/10.1016/j.ijpharm.2018.04.061 PMID: 29715533

[4] Gorain, B.; Choudhury, H.; Pandey, M.; Mohd Amin, M.C.I.; Singh, B.; Gupta, U. Dendrimers as Effective Carriers for the Treatment of Brain Tumor.Nanotechnology-Based Target. Drug Deliv. Syst. Brain Tumors; Elsevier, 2018, pp. 267-305. http ://dx.doi.org/10.1016/B978-0-12-812218-1.00010-5

[5] Cui, W.; Li, J.; Decher, G. Self-Assembled Smart Nanocarriers for Targeted Drug Delivery. Adv. Mater., 2016, 28(6), 1302-1311. http ://dx.doi.org/10.1002/adma.201502479 PMID: 26436442 
[6] Choudhury, H.; Gorain, B.; Pandey, M.; Kumbhar, S.A.; Tekade, R.K.; Iyer, A.K.; Kesharwani, P. Recent advances in TPGS-based nanoparticles of docetaxel for improved chemotherapy. Int. J. Pharm., 2017, 529(1-2), 506-522.

http ://dx.doi.org/10.1016/j.ijpharm.2017.07.018 PMID: 28711640

[7] Jones, A.T.; Gumbleton, M.; Duncan, R. Understanding endocytic pathways and intracellular trafficking : a prerequisite for effective design of advanced drug delivery systems,, 2003, 55(2003), 13531357.

http ://dx.doi.org/10.1016/j.addr.2003.07.002

[8] Sun, J.; Hee, T.; Yong, K.; Soo, S.; Jin, J. $N$-acetyl histidineconjugated glycol chitosan self-assembled nanoparticles for intracytoplasmic delivery of drugs : Endocytosis, exocytosis and drug release, 2006, 115(2006), 37-45.

http ://dx.doi.org/10.1016/j.jconrel.2006.07.011

[9] Hyung, J.; Kwon, S.; Lee, M.; Chung, H.; Kim, J.; Kim, Y. Selfassembled nanoparticles based on glycol chitosan bearing hydrophobic moieties as carriers for doxorubicin : In vivo biodistribution and anti-tumor activity,, 2006, 27(2006), 119-126.

http ://dx.doi.org/10.1016/j.biomaterials.2005.05.028

[10] Kesharwani, P.; Tekade, R.K.; Gajbhiye, V.; Jain, K.; Jain, N.K. Cancer targeting potential of some ligand-anchored poly(propylene imine) dendrimers: a comparison. Nanomedicine (Lond.), 2011, 7(3), 295-304.

http ://dx.doi.org/10.1016/j.nano.2010.10.010 PMID: 21070888

[11] Cao, Y.; Gu, Y.; Ma, H.; Bai, J.; Liu, L.; Zhao, P. International Journal of Biological Macromolecules Self-assembled nanoparticle drug delivery systems from galactosylated polysaccharide - doxorubicin conjugate loaded doxorubicin, 2010, 46(2010), 245-249. http ://dx.doi.org/10.1016/j.ijbiomac.2009.11.008

[12] Kesharwani, P.; Banerjee, S.; Gupta, U.; Mohd Amin, M.C.I.; Padhye, S.; Sarkar, F.H. PAMAM dendrimers as promising nanocarriers for RNAi therapeutics. Mater. Today, 2015. http ://dx.doi.org/10.1016/j.mattod.2015.06.003

[13] Shukla, R.; Handa, M.; Lokesh, S.B.; Ruwali, M.; Kohli, K. Conclusion and Future Prospective of Polymeric Nanoparticles for Cancer Therapy, Polym. Nanoparticles as a Promis; Tool AntiCancer Ther, 2019, pp. 389-408.

[14] Sun, L. Peptide Self-assembled Nanostructures for Drug Delivery Applications (n.d.).,

[15] Fan, Z.; Sun, L.; Huang, Y.; Wang, Y.; Zhang, M. Bioinspired fluorescent dipeptide nanoparticles for targeted cancer cell imaging and real-time monitoring of drug release. Nat. Nanotechnol., 2016, 11(4), 388-394.

http ://dx.doi.org/10.1038/nnano.2015.312 PMID: 26751169

[16] Gorain, B.; Choudhury, H.; Pandey, M.; Nair, A.B.; Iqbal Mohd Amin, M.C.; Molugulu, N. Dendrimer-Based Nanocarriers in Lung Cancer Therapy, Nanotechnology-Based Target. Drug Deliv. Syst. Lung Cancer., 2019, 161-192.

[17] Jain, A.; Kesharwani, P.; Garg, N.K.; Jain, A.; Jain, S.A.; Jain, A.K.; Nirbhavane, P.; Ghanghoria, R.; Tyagi, R.K.; Katare, O.P. Galactose engineered solid lipid nanoparticles for targeted delivery of doxorubicin. Colloids Surf. B Biointerfaces, 2015, 134, 47-58. http ://dx.doi.org/10.1016/j.colsurfb.2015.06.027 PMID: 26142628

[18] Larson, N.; Greish, K.; Bauer, H.; Maeda, H.; Ghandehari, H. Synthesis and evaluation of poly(styrene-co-maleic acid) micellar nanocarriers for the delivery of tanespimycin. Int. J. Pharm., 2011, 420(1), 111-117.

http ://dx.doi.org/10.1016/j.ijpharm.2011.08.011 PMID: 21856392

[19] Shi, J.; Xiao, Z.; Kamaly, N.; Farokhzad, O.C. Self-assembled targeted nanoparticles: evolution of technologies and bench to bedside translation. Acc. Chem. Res., 2011, 44(10), 1123-1134. http ://dx.doi.org/10.1021/ar200054n PMID: 21692448

[20] Ariga, K.; Hill, J.P.; Lee, M.V.; Lee, Y.; Chen, Y.; Tarasova, N.I. to study protein unfolding Self-assembled peptide nanostructures for functional materials. Nanotechnology, 27, 1-37. n.d. http ://dx.doi.org/10.1088/0957-4484/27/40/402002

[21] Vermant, J.; Grzelczak, M.; Vermant, J.; Furst, E.M.; Liz-marza, L.M. Directed Self-Assembly of Nanoparticles, 2010, 3591-3605. http ://dx.doi.org/10.1021/nn100869j

[22] Park, S. Understanding the Self-Assembly Behavior of Nanoparticles and Polymers, n.d.

[23] Lu, H.; Wang, J.; Wang, T.; Zhong, J.; Bao, Y.; Hao, H. Recent Progress on Nanostructures for Drug Delivery Applications, 2016, (2016)
[24] Shcherbina, M.A.; Chvalun, S.N. Driving Forces of the SelfAssembly of Supramolecular Systems. Partially Ordered Mesophases, 2018, 92, 1161-1170.

http ://dx.doi.org/10.1134/S003602441806016X

[25] Tan, S.; Zou, C.; Zhang, W.; Yin, M.; Gao, X.; Tang, Q. Recent developments in $\mathrm{d}-\alpha$-tocopheryl polyethylene glycol-succinatebased nanomedicine for cancer therapy. Drug Deliv., 2017, 24(1), 1831-1842.

http ://dx.doi.org/10.1080/10717544.2017.1406561 PMID:

29182031

[26] Singh, A.; Vaishagya, K.; K Verma, R.; Shukla, R. Temperature/pH-Triggered PNIPAM-Based Smart Nanogel System Loaded With Anastrozole Delivery for Application in Cancer Chemotherapy. AAPS PharmSciTech, 2019, 20(5), 213.

http ://dx.doi.org/10.1208/s12249-019-1410-3 PMID: 31165298

[27] Shukla, R.; Kumar, J.; Dwivedi, P.; Gatla, P.; Mishra, P.R. Microparticles of diethylcarbamazine citrate for the treatment of lymphatic filariasis.Asian J; Chem, 2013.

[28] Ghadiri, M.; Vasheghani-Farahani, E.; Atyabi, F.; Kobarfard, F.; Mohamadyar-Toupkanlou, F.; Hosseinkhani, H. Transferrinconjugated magnetic dextran-spermine nanoparticles for targeted drug transport across blood-brain barrier. J. Biomed. Mater. Res. A, 2017, 105(10), 2851-2864

http ://dx.doi.org/10.1002/jbm.a.36145 PMID: 28639394

[29] Yan, Y.; Zhou, K.; Xiong, H.; Miller, J.B.; Motea, E.A.; Boothman, D.A.; Liu, L.; Siegwart, D.J. Aerosol delivery of stabilized polyester-siRNA nanoparticles to silence gene expression in orthotopic lung tumors. Biomaterials, 2017, 118, 84-93.

http ://dx.doi.org/10.1016/j.biomaterials.2016.12.001 PMID: 27974266

[30] Jing, X.; Mi, H-Y.; Peng, J.; Peng, X-F.; Turng, L-S. Electrospun aligned poly(propylene carbonate) microfibers with chitosan nanofibers as tissue engineering scaffolds. Carbohydr. Polym., 2015, 117, 941-949.

http ://dx.doi.org/10.1016/j.carbpol.2014.10.025 PMID: 25498720

[31] Zhou, J.; Xu, R.; Yin, C.; Li, Z.; Wu, W.; Wu, M. In situ growth of polyphosphazene nanoparticles on graphene sheets as a highly stable nanocomposite for metal-free lithium anodes. RSC Advances, 2016, 6, 62005-62010.

http ://dx.doi.org/10.1039/C6RA11597G

[32] Faridirad, F.; Ahmadi, S.; Barmar, M. Polyamide/Carbon Nanoparticles Nanocomposites: A Review. Polym. Eng. Sci., 2017, 57, 475494.

http ://dx.doi.org/10.1002/pen.24444

[33] Pardhi, V.P.; Verma, T.; Flora, S.J.S.; Chandasana, H.; Shukla, R. Nanocrystals: An Overview of Fabrication, Characterization and Therapeutic Applications in Drug Delivery. Curr. Pharm. Des., 2019.

http ://dx.doi.org/10.2174/1381612825666190215121148 PMID: 30767737

[34] Jain, V.; Singodia, D.; Gupta, G.K.; Garg, D.; Keshava, G.B.S.; Shukla, R.; Shukla, P.K.; Mishra, P.R. Ciprofloxacin surf-plexes in sub-micron emulsions: a novel approach to improve payload efficiency and antimicrobial efficacy. Int. J. Pharm., 2011, 409(1-2), 237-244.

http ://dx.doi.org/10.1016/j.ijpharm.2011.02.020 PMID: 21356290

[35] Shukla, R.; Gupta, J.; Shukla, P.; Dwivedi, P.; Tripathi, P.; Bhattacharya, S.M. Chitosan coated alginate micro particles for the oral delivery of antifilarial drugs and combinations for intervention in Brugia malayi induced lymphatic filariasis; RSC Adv, 2015.

http ://dx.doi.org/10.1039/C5RA06982C

[36] Singodia, D.; Kansal, S.; Verma, A.; Shukla, R.; Shukla, P.; Dwivedi, P. Development of nevirapine loaded novel surfactant free polymeric emulsion and investigations for its suitability as drug delivery vehicle, J. Bionanoscience., 2010. http ://dx.doi.org/10.1166/jbns.2010.1029

[37] Ahmad, Z.; Shah, A.; Siddiq, M.; Kraatz, H-B. Polymeric micelles as drug delivery vehicles. RSC Advances, 2014, 4, 17028-17038. http ://dx.doi.org/10.1039/C3RA47370H

[38] Kim, G.; Piao, C.; Oh, J.; Lee, M. Self-assembled polymeric micelles for combined delivery of anti-inflammatory gene and drug to the lungs by inhalation. Nanoscale, 2018, 10(18), 8503-8514. http ://dx.doi.org/10.1039/C8NR00427G PMID: 29693671 
[39] Piao, C.; Park, J.H.; Lee, M. Anti-Inflammatory Therapeutic Effect of Adiponectin Gene Delivery Using a Polymeric Carrier in an Acute Lung Injury Model. Pharm. Res., 2017, 34(7), 1517-1526. http ://dx.doi.org/10.1007/s11095-017-2175-6 PMID: 28493099

[40] Kim, H.A.; Park, J.H.; Lee, S.; Choi, J.S.; Rhim, T.; Lee, M. Combined delivery of dexamethasone and plasmid DNA in an animal model of LPS-induced acute lung injury. J. Control. Release, 2011, 156(1), 60-69.

http ://dx.doi.org/10.1016/j.jconrel.2011.06.041 PMID: 21763372

[41] D'souza, A.A.; Shegokar, R. Polyethylene glycol (PEG): a versatile polymer for pharmaceutical applications. Expert Opin. Drug Deliv., 2016, 13(9), 1257-1275.

http ://dx.doi.org/10.1080/17425247.2016.1182485 PMID: 27116988

[42] Tang, Z.; He, C.; Tian, H.; Ding, J.; Hsiao, B.S.; Chu, B. Polymeric nanostructured materials for biomedical applications. Prog. Polym. Sci., 2016, 60, 86-128.

http ://dx.doi.org/10.1016/j.progpolymsci.2016.05.005

[43] Sevink, G.J.A.; Zvelindovsky, A.V. Self-assembly of complex vesicles. Macromolecules, 2005, 38, 7502-7512.

http ://dx.doi.org/10.1021/ma0506740

[44] Blanazs, A.; Armes, S.P.; Ryan, A.J. Self-Assembled Block Copolymer Aggregates: From Micelles to Vesicles and their Biological Applications. Macromol. Rapid Commun., 2009, 30(4-5), 267-277. http ://dx.doi.org/10.1002/marc.200800713 PMID: 21706604

[45] Koide, A.; Kishimura, A.; Osada, K.; Jang, W-D.; Yamasaki, Y.; Kataoka, K. Semipermeable polymer vesicle (PICsome) selfassembled in aqueous medium from a pair of oppositely charged block copolymers: physiologically stable micro-/nanocontainers of water-soluble macromolecules. J. Am. Chem. Soc., 2006, 128(18), 5988-5989.

http ://dx.doi.org/10.1021/ja057993r PMID: 16669639

[46] Yaşayan, G.; Redhead, M.; Magnusson, J.P.; Spain, S.G.; Allen, S.; Davies, M. Well-defined polymeric vesicles with high stability and modulation of cell uptake by a simple coating protocol. Polym. Chem., 2012, 3, 2596.

http ://dx.doi.org/10.1039/c2py20352a

[47] Bermúdez, H.; Hammer, D.A.; Discher, D.E. Effect of bilayer thickness on membrane bending rigidity. Langmuir, 2004, 20(3), 540-543.

http ://dx.doi.org/10.1021/la035497f PMID: 15773070

[48] Battaglia, G.; Ryan, A.J. Pathways of polymeric vesicle formation. J. Phys. Chem. B, 2006, 110(21), 10272-10279.

http ://dx.doi.org/10.1021/jp060728n PMID: 16722729

[49] Chacko, R.T.; Ventura, J.; Zhuang, J.; Thayumanavan, S. Polymer nanogels: a versatile nanoscopic drug delivery platform. Adv. Drug Deliv. Rev., 2012, 64(9), 836-851.

http ://dx.doi.org/10.1016/j.addr.2012.02.002 PMID: 22342438

[50] Rigogliuso, S.; Sabatino, M.A.; Adamo, G.; Grimaldi, N.; Dispenza, C.; Ghersi, G. Nanocarriers for Drug Delivery Application. Chem. Eng. Trans., 2012, 27, 247-252.

[51] Ferreira, S.A.; Gama, F.M.; Vilanova, M. Polymeric nanogels as vaccine delivery systems. Nanomedicine (Lond.), 2013, 9(2), 159173 .

http ://dx.doi.org/10.1016/j.nano.2012.06.001 PMID: 22772049

[52] Choudhury, H.; Gorain, B.; Pandey, M.; Chatterjee, L.A.; Sengupta, P.; Das, A.; Molugulu, N.; Kesharwani, P. Recent update on nanoemulgel as topical drug delivery system. J. Pharm. Sci., 2017, 106(7), 1736-1751.

http ://dx.doi.org/10.1016/j.xphs.2017.03.042 PMID: 28412398

[53] Kabanov, A.V.; Vinogradov, S.V. Nanogels as pharmaceutical carriers: finite networks of infinite capabilities. Angew. Chem. Int. Ed. Engl., 2009, 48(30), 5418-5429.

http ://dx.doi.org/10.1002/anie.200900441 PMID: 19562807

[54] Akiyoshi, K.; Kobayashi, S.; Shichibe, S.; Mix, D.; Baudys, M.; Kim, S.W.; Sunamoto, J. Self-assembled hydrogel nanoparticle of cholesterol-bearing pullulan as a carrier of protein drugs: complexation and stabilization of insulin. J. Control. Release, 1998, 54(3), 313-320.

http ://dx.doi.org/10.1016/S0168-3659(98)00017-0 PMID: 9766251

[55] He, J.; Yan, B.; Tremblay, L.; Zhao, Y. Both core- and shell-crosslinked nanogels: photoinduced size change, intraparticle LCST, and interparticle UCST thermal behaviors. Langmuir, 2011, 27(1), 436444.

http ://dx.doi.org/10.1021/la1040322 PMID: 21141813
[56] Ferreira, L.S.; Trierweiler, J.O. Modeling and simulation of the polymeric nanocapsule formation process in: IFAC Proc. Vol, 2009, pp. 405-410.

http ://dx.doi.org/10.3182/20090712-4-TR-2008.00064

[57] Stewart, S.; Liu, G. Hollow Nanospheres from Polyisoprene-blockpoly(2-cinnamoylethyl methacrylate)-block-poly(tert-butyl acrylate). Chem. Mater., 1999, 11, 1048-1054.

http ://dx.doi.org/10.1021/cm981009r

[58] Dash, B.C.; Réthoré, G.; Monaghan, M.; Fitzgerald, K.; Gallagher, W.; Pandit, A. The influence of size and charge of chitosan/polyglutamic acid hollow spheres on cellular internalization, viability and blood compatibility. Biomaterials, 2010, 31(32), 8188-8197.

http ://dx.doi.org/10.1016/j.biomaterials.2010.07.067 PMID: 20701967

[59] Gorain, B.; Tekade, M.; Kesharwani, P.; Iyer, A.K.; Kalia, K.; Tekade, R.K. The use of nanoscaffolds and dendrimers in tissue engineering. Drug Discov. Today, 2017, 22(4), 652-664.

http ://dx.doi.org/10.1016/j.drudis.2016.12.007 PMID: 28219742

[60] Kesharwani, P.; Choudhury, H.; Meher, J.G.; Pandey, M.; Gorain, B. Dendrimer-entrapped gold nanoparticles as promising nanocarriers for anticancer therapeutics and imaging. Prog. Mater. Sci., 2019, 103, 484-508.

http ://dx.doi.org/10.1016/j.pmatsci.2019.03.003

[61] Gupta, U.; Agashe, H.B.; Asthana, A.; Jain, N.K. Dendrimers: novel polymeric nanoarchitectures for solubility enhancement. $\mathrm{Bi}$ omacromolecules, 2006, 7(3), 649-658.

http ://dx.doi.org/10.1021/bm050802s PMID: 16529394

[62] Kesharwani, P.; Iyer, A.K. Recent advances in dendrimer-based nanovectors for tumor-targeted drug and gene delivery. Drug Discov. Today, 2015, 20(5), 536-547.

http ://dx.doi.org/10.1016/j.drudis.2014.12.012 PMID: 25555748

[63] Sharma, A.K.; Gothwal, A.; Kesharwani, P.; Alsaab, H.; Iyer, A.K.; Gupta, U. Dendrimer nanoarchitectures for cancer diagnosis and anticancer drug delivery. Drug Discov. Today, 2017, 22(2), 314-326.

http ://dx.doi.org/10.1016/j.drudis.2016.09.013 PMID: 27671487

[64] Tripathi, P.K.; Gorain, B.; Choudhury, H.; Srivastava, A.; Kesharwani, P. Dendrimer entrapped microsponge gel of dithranol for effective topical treatment. Heliyon, 2019, 5(3)e 01343 http ://dx.doi.org/10.1016/j.heliyon.2019.e01343 PMID: 30957038

[65] Pandey, D.; Kesharwani, P.; Jain, D. Entrapment of drug-sorbate complex in submicron emulsion: A potential approach to improve antimicrobial activity in bacterial corneal infection. J. Drug Deliv. Sci. Technol., 2019, 49, 455-462.

http ://dx.doi.org/10.1016/j.jddst.2018.12.006

[66] Ptorchilin, V. Drug Carriers, n.d.

[67] Gorain, B.; Choudhury, H.; Pandey, M.; Kokare, C.; Khurana, R.K.; Sehdev, A. Polyester, Polyhydroxyalkanoate Nanoparticles as a Promising Tool for Anticancer Therapeutics, Polym. Nanoparticles as a Promis; Tool Anti-Cancer Ther, 2019, pp. 101-121. http ://dx.doi.org/10.1016/B978-0-12-816963-6.00006-6

[68] Stephanopoulos, N.; Ortony, J.H.; Stupp, S.I. Self-assembly for the synthesis of functional biomaterials. Acta Mater., 2013, 61(3), 912930.

http ://dx.doi.org/10.1016/j.actamat.2012.10.046 PMID: 23457423

[69] Shukla, R.; Singh, A.; Pardhi, V.; Kashyap, K.; Dubey, S.K.; Dandela, R. Dendrimer-Based Nanoparticulate Delivery System for Cancer Therapy, Polym. Nanoparticles as a Promis; Tool AntiCancer Ther, 2019, pp. 233-255.

[70] Liu, K.; Li, H.; Williams, G.R.; Wu, J.; Zhu, L-M. pH-responsive liposomes self-assembled from electrosprayed microparticles, and their drug release properties. Colloids Surf. A Physicochem. Eng. Asp., 2018, 537, 20-27.

http ://dx.doi.org/10.1016/j.colsurfa.2017.09.046

[71] Choudhury, H.; Pandey, M.; Gorain, B.; Chatterjee, B.; Madheswaran, T.; Md, S. Nanoemulsions as Effective Carriers for the Treatment of Lung Cancer, Nanotechnology-Based Target Drug Deliv. Syst. Lung Cancer, 2019, 217-247. http ://dx.doi.org/10.1016/B978-0-12-815720-6.00009-5

[72] Gorain, B.; Bhattamishra, S.K.; Choudhury, H.; Nandi, U.; Pandey, M. Overexpressed Receptors and Proteins in Lung Cancer, Nanotechnology-Based Target. Drug Deliv. Syst. Lung Cancer., 2019, 39-75.

http ://dx.doi.org/10.1016/B978-0-12-815720-6.00003-4 
[73] Yu, D-G.; Yang, J-H.; Wang, X.; Tian, F. Liposomes selfassembled from electrosprayed composite microparticles. Nanotechnology, 2012, 23(10)105606

http ://dx.doi.org/10.1088/0957-4484/23/10/105606 PMID 22362251

[74] Lo, C.T.; Jahn, A.; Locascio, L.E.; Vreeland, W.N. Controlled selfassembly of monodisperse niosomes by microfluidic hydrodynamic focusing. Langmuir, 2010, 26(11), 8559-8566. http ://dx.doi.org/10.1021/la904616s PMID: 20146467

[75] Dwivedi, N.; Shah, J.; Mishra, V.; Tambuwala, M.; Kesharwani, P. Nanoneuromedicine for management of neurodegenerative disorder. J. Drug Deliv. Sci. Technol., 2019, 49, 477-490. http ://dx.doi.org/10.1016/j.jddst.2018.12.021

[76] Nagalakshmi, S.; Krishnaraj, K.; Jothy, M.A.; Chaudhari, P.S.; Pushpalatha, H.; Shanmuganthan, S. Fabrication and Characterization of Herbal Drug-Loaded Nonionic Surfactant Based Niosomal Topical Gel. J. Pharm. Sci. Res., 2016, 8, 1271-1278.

[77] Pandey, M.; Choudhury, H.; Yi, C.X.; Mun, C.W.; Phing, G.K.; Rou, G.X.; Singh, B.J.K.A.A.J.; Jhee, A.N.A.; Chin, L.K.; Kesharwani, P.; Gorain, B.; Hussain, Z. Recent Updates on Novel Approaches in Insulin Drug Delivery: A Review of Challenges and Pharmaceutical Implications. Curr. Drug Targets, 2018, 19(15), $1782-1800$.

http ://dx.doi.org/10.2174/1389450119666180523092100 PMID: 29792143

[78] Meher, J.G.; Dixit, S.; Pathan, D.K.; Singh, Y.; Chandasana, H.; Pawar, V.K.; Sharma, M.; Bhatta, R.S.; Konwar, R.; Kesharwani, P.; Chourasia, M.K. Paclitaxel-loaded TPGS enriched selfemulsifying carrier causes apoptosis by modulating survivin expression and inhibits tumour growth in syngeneic mammary tumours. Artif. Cells Nanomed. Biotechnol., 2018, 46(sup3), S344S358.

http ://dx.doi.org/10.1080/21691401.2018.1492933 PMID: 30282466

[79] Shi, J.; Xiao, Z.; Votruba, A.R.; Vilos, C.; Farokhzad, O.C. Differentially charged hollow core/shell lipid-polymer-lipid hybrid nanoparticles for small interfering RNA delivery. Angew. Chem. Int. Ed. Engl., 2011, 50(31), 7027-7031.

http ://dx.doi.org/10.1002/anie.201101554 PMID: 21698724

[80] Tambuwala, M.M.; Kesharwani, P.; Shukla, R.; Thompson, P.D.; McCarron, P.A. Caffeic acid phenethyl ester (CAPE) reverses fibrosis caused by chronic colon inflammation in murine model of colitis. Pathol. Res. Pract., 2018, 214(11), 1909-1911.

http ://dx.doi.org/10.1016/j.prp.2018.08.020 PMID: 30170869

[81] Shen, H.; Zhang, L.; Liu, M.; Zhang, Z. Biomedical applications of graphene. Theranostics, 2012, 2(3), 283-294.

http ://dx.doi.org/10.7150/thno.3642 PMID: 22448195

[82] Bakshi, H.A.; Mishra, V.; Satija, S.; Mehta, M.; Hakkim, F.L.; Kesharwani, P. Dynamics of Prolyl Hydroxylases Levels During Disease Progression in Experimental Colitis, Inflammation, 2019, $1-5$.

http ://dx.doi.org/10.1007/s10753-019-01065-3

[83] (PDF) Graphene-Nanoparticle Composites and, n.d.

[84] Choudhury, H.; Gorain, B.; Pandey, M.; Khurana, R.K.; Kesharwani, P. Strategizing biodegradable polymeric nanoparticles to cross the biological barriers for cancer targeting. Int. J. Pharm., 2019, 565, 509-522.

http ://dx.doi.org/10.1016/j.ijpharm.2019.05.042 PMID: 31102804

[85] Zhu, Z.; Su, D.; Weinberg, G.; Schlögl, R. Supermolecular SelfAssembly of Graphene Sheets: Formation of Tube-in-Tube Nanostructures. Nano Lett., 2004, 4, 2255-2259.

http ://dx.doi.org/10.1021/n1048794t

[86] Zeeshan, F.; Tabbassum, M.; Kesharwani, P. Investigation on Secondary Structure Alterations of Protein Drugs as an Indicator of Their Biological Activity Upon Thermal Exposure. Protein J., 2019, 38(5), 551-564.

http ://dx.doi.org/10.1007/s10930-019-09837-4 PMID: 31054037

[87] Wu, Q.; Xu, Y.; Yao, Z.; Liu, A.; Shi, G. Supercapacitors based on flexible graphene/polyaniline nanofiber composite films. ACS Nano, 2010, 4(4), 1963-1970.

http ://dx.doi.org/10.1021/nn1000035 PMID: 20355733

[88] Cai, D.; Song, M. Recent advance in functionalized graphene/polymer nanocomposites. J. Mater. Chem., 2010, 20, 7906. http ://dx.doi.org/10.1039/c0jm00530d

[89] Choudhury, H.; Pandey, M.; Yin, T.H.; Kaur, T.; Jia, G.W.; Tan, S.Q.L.; Weijie, H.; Yang, E.K.S.; Keat, C.G.; Bhattamishra, S.K.;
Kesharwani, P.; Md, S.; Molugulu, N.; Pichika, M.R.; Gorain, B. Rising horizon in circumventing multidrug resistance in chemotherapy with nanotechnology. Mater. Sci. Eng. C, 2019, 101, 596613.

http ://dx.doi.org/10.1016/j.msec.2019.04.005 PMID: 31029353

[90] Wang, H.; Casalongue, H.S.; Liang, Y.; Dai, H. Ni(OH $)_{2}$ nanoplates grown on graphene as advanced electrochemical pseudocapacitor materials. J. Am. Chem. Soc., 2010, 132(21), 7472-7477. http ://dx.doi.org/10.1021/ja102267j PMID: 20443559

[91] Cong, H-P.; Ren, X-C.; Wang, P.; Yu, S-H. Macroscopic multifunctional graphene-based hydrogels and aerogels by a metal ion induced self-assembly process. ACS Nano, 2012, 6(3), 2693-2703. http ://dx.doi.org/10.1021/nn300082k PMID: 22303866

[92] Chen, W.; Yan, L. In situ self-assembly of mild chemical reduction graphene for three-dimensional architectures. Nanoscale, 2011, 3(8), 3132-3137.

http ://dx.doi.org/10.1039/c1nr10355e PMID: 21698339

[93] Chen, W.; Li, S.; Chen, C.; Yan, L. Self-assembly and embedding of nanoparticles by in situ reduced graphene for preparation of a 3D graphene/nanoparticle aerogel. Adv. Mater., 2011, 23(47), 5679-5683.

http ://dx.doi.org/10.1002/adma.201102838 PMID: 22052602

[94] Gorain, B.; Choudhury, H.; Pandey, M.; Kesharwani, P.; Abeer, M.M.; Tekade, R.K.; Hussain, Z. Carbon nanotube scaffolds as emerging nanoplatform for myocardial tissue regeneration: A review of recent developments and therapeutic implications. Biomed. Pharmacother., 2018, 104, 496-508.

http ://dx.doi.org/10.1016/j.biopha.2018.05.066 PMID: 29800914

[95] Luo, S.; Luo, Y.; Wu, H.; Li, M.; Yan, L.; Jiang, K.; Liu, L.; Li, Q.; Fan, S.; Wang, J. Self-assembly of 3D Carbon Nanotube Sponges: A Simple and Controllable Way to Build Macroscopic and Ultralight Porous Architectures. Adv. Mater., 2017, 29(1)1603549 http ://dx.doi.org/10.1002/adma.201603549 PMID: 27805759

[96] Kim, S.H.; Kaplan, J.A.; Sun, Y.; Shieh, A.; Sun, H-L.; Croce, C.M.; Grinstaff, M.W.; Parquette, J.R. The self-assembly of anticancer camptothecin-dipeptide nanotubes: a minimalistic and high drug loading approach to increased efficacy. Chemistry, 2015, 2l(1), 101-105.

http ://dx.doi.org/10.1002/chem.201404520 PMID: 25384556

[97] Bolskar, R.D. Fullerenes for Drug Delivery.Encycl. Nanotechnol; Springer Netherlands: Dordrecht, 2016, pp. 1267-1281.

http ://dx.doi.org/10.1007/978-94-017-9780-1_76

[98] Li, F.; Yager, K.G.; Dawson, N.M.; Jiang, Y-B.; Malloy, K.J.; Qin, Y. Nano-structuring polymer/fullerene composites through the interplay of conjugated polymer crystallization, block copolymer self-assembly and complementary hydrogen bonding interactions. Polym. Chem., 2015, 6, 721-731.

http ://dx.doi.org/10.1039/C4PY00934G

[99] Kim, K-H.; Ko, D-K.; Kim, Y-T.; Kim, N.H.; Paul, J.; Zhang, SQ.; Murray, C.B.; Acharya, R.; DeGrado, W.F.; Kim, Y.H.; Grigoryan, G. Protein-directed self-assembly of a fullerene crystal. Nat. Commun., 2016, 7, 11429.

http ://dx.doi.org/10.1038/ncomms11429 PMID: 27113637

[100] Mesoporous silica nanoparticles in target drug delivery system. RE:view, n.d.

[101] Banik, M.; Basu, T. their synthesis , characterization and mode of, 2014.

http ://dx.doi.org/10.1039/c3dt52522h.

[102] Hayes, M.E.; Drummond, D.C.; Kirpotin, D.B.; Zheng, W.W.; Noble, C.O.; Park, J.W.; Marks, J.D.; Benz, C.C.; Hong, K. Genospheres: self-assembling nucleic acid-lipid nanoparticles suitable for targeted gene delivery. Gene Ther., 2006, 13(7), 646-651. http ://dx.doi.org/10.1038/sj.gt.3302699 PMID: 16341056

[103] Kundu, A.; Nandi, S.; Nandi, A.K. Progress in Materials Science Nucleic acid based polymer and nanoparticle conjugates : Synthesis, properties and applications. Prog. Mater. Sci., 2017, 88, 136185.

http ://dx.doi.org/10.1016/j.pmatsci.2017.04.001

[104] Goldberg, M.; Langer, R.; Jia, X. Nanostructured materials for applications in drug delivery and tissue engineering. J. Biomater. Sci. Polym. Ed., 2007, 18(3), 241-268. http

://www.ncbi.nlm.nih.gov/pubmed/17471764 http ://dx.doi.org/10.1163/156856207779996931 PMID: 17471764

[105] Cheetham, A.G.; Zhang, P.; Lin, Y.A.; Lock, L.L.; Cui, H. Supramolecular nanostructures formed by anticancer drug assembly. $J$. Am. Chem. Soc., 2013, 135(8), 2907-2910. 
http ://dx.doi.org/10.1021/ja3115983 PMID: 23379791

[106] Lock, L.L.; LaComb, M.; Schwarz, K.; Cheetham, A.G.; Lin, Y.A.; Zhang, P.; Cui, H. Self-assembly of natural and synthetic drug amphiphiles into discrete supramolecular nanostructures. Faraday Discuss., 2013, 166, 285-301. http ://dx.doi.org/10.1039/c3fd00099k PMID: 24611283

[107] Li, H.; Kan, C.; Yi, Z.; Ding, X.; Cao, Y.; Zhu, J. Synthesis of One Dimensional Gold Nanostructures. J. Nanomater., 2010, 2010, 1-8. http ://dx.doi.org/10.1155/2010/962718 